\title{
An Elevation of Serum Ferritin Level Might Increase Clinical Risk for the Persistence of Patent Ductus Arteriosus, Sepsis and Bronchopulmonary Dysplasia in Erythropoietin-Treated Very-Low-Birth-Weight Infants
}

\author{
Masayuki Ochiai ${ }^{a, c}$ Hiroaki Kurata ${ }^{a, c}$ Hirosuke Inoue ${ }^{a, c}$ Koichi Tanaka ${ }^{a, c}$ \\ Yuki Matsushita ${ }^{a, c}$ Junko Fujiyoshi, ${ }^{a, c}$ Yoshifumi Wakata ${ }^{b} K_{\text {Kiyoko Kato }}{ }^{a} d$ \\ Tomoaki Taguchia, e Hidetoshi Takadac, $f$
}

Centers of a Comprehensive Maternity and Perinatal Care and ${ }^{\mathrm{b}}$ Medical Information, Kyushu University Hospital, and Departments of ${ }^{\mathrm{C} P e d i a t r i c s,}{ }^{\mathrm{d}}$ Obstetrics and Gynecology, ePediatric Surgery and ${ }^{\mathrm{f}}$ Perinatal and Pediatric Medicine, Graduate School of Medical Sciences, Kyushu University, Fukuoka, Japan

\section{Key Words}

Anemia of prematurity · Iron supplementation .

Erythropoietin $\cdot$ Blood transfusion

\begin{abstract}
Background: The substantial risk of iron overload is not routinely monitored in most of the neonatal intensive care units (NICUs) in Japan; however, blood transfusion is an essential strategy for successfully treating preterm low-birth-weight infants. Objective: The aim of this study was to investigate the iron status and clinical features of infants with a birth weight of $<1,500 \mathrm{~g}$, i.e. very-low-birth-weight infants (VLBWIs).Methods: This prospective observational study enrolled $176(82.6 \%)$ patients from a total of 213 VLBWIs admitted to our NICU from 2009 to 2014. Clinical information was collected including maternal records and infant morbidity and treatment. Management strategies including enteral iron supplementation, erythropoietin administration and
\end{abstract}

blood transfusion were allowed according to the consensus in Japan. The hematological status was surveyed from birth to 12 postnatal weeks of age. The iron status was determined according to serum iron, unbound iron-binding capacity and serum ferritin. The definition of hyperferritinemia was set as a value of $\geq 500 \mathrm{ng} / \mathrm{ml}$. Results: Twenty-four (13.6\%) infants displayed hyperferritinemia. A multiple logistic analysis selected 3 associated factors of hyperferritinemia: surgical ligation for patent ductus arteriosus, sepsis and moderate or severe states of bronchopulmonary dysplasia. We also verified that the value of ferritin was significantly correlated with those of aspartate transaminase, creatine kinase and C-reactive protein according to a multilinear regression analysis. After excluding the ferritin data of these outliers, we did not observe any factors associated with hyperferritinemia. Conclusions: Hyperferritinemia might be associated with oxygen radical diseases and susceptibility to infection.

(c) 2016 The Author(s)

Published by S. Karger AG, Basel

\begin{tabular}{ll}
\hline KARGER & $\begin{array}{l}\text { @ } 2016 \text { The Author(s) } \\
\text { Published by S. Karger AG, Basel }\end{array}$ \\
$\begin{array}{l}\text { E-Mail karger@karger.com } \\
\text { Open carccess }\end{array}$ \\
www.karger.com/neo & $\begin{array}{l}\text { This article is licensed under the Creative Commons Attribution- } \\
\text { NonCommercial-NoDerivatives 4.0 International License (CC BY- } \\
\text { NC-ND) (http://www.karger.com/Services/OpenAccessLicense). } \\
\text { Usage and distribution for commercial purposes as well as any dis- } \\
\text { tribution of modified material requires written permission. }\end{array}$
\end{tabular}

Masayuki Ochiai

Department of Pediatrics, Graduate School of Medical Sciences, Kyushu University 3-1-1 Maidashi, Higashi-ku

Fukuoka 812-8582 (Japan)

E-Mail ochimasa@ pediatr.med.kyushu-u.ac.jp 


\section{Introduction}

Advances in perinatal medicine have contributed to remarkable improvements in the survival rates of verylow-birth-weight infants (VLBWIs), a group of preterm infants weighing $<1,500 \mathrm{~g}$ at birth $[1,2]$. VLBWIs frequently undergo transfusion because they are critically ill, often require surgical procedures and have the highest blood sampling loss in relation to their weight. Frequent transfusion results in an accumulation of excess iron. Although very preterm infants have a substantial risk of iron overload, the kinetics of the iron status are not routinely monitored in most neonatal intensive care units (NICUs) in Japan.

Iron is a vital micronutrient for critical functions in all species. On the other hand, iron overload generates free radicals via the Fenton and Haber-Weiss reactions [3]. Preterm LBWIs possess little antioxidant protection so they are especially susceptible to oxygen radical injuries [4]. Oxidative stress is thought to contribute to aggravations of 'oxygen radical disease in neonates' [5] including necrotizing enterocolitis, intraventricular hemorrhage $(\mathrm{IVH})$, periventricular leukomalacia (PVL), retinopathy of prematurity (ROP) and neonatal bronchopulmonary dysplasia (BPD) [6]. Additionally, the iron microenvironment enables the alteration of host immune regulation and increases susceptibility to infection $[7,8]$. In this study, we investigated the iron and hematological status of VLBWIs requiring intensive care and their relationships with oxygen radical diseases and susceptibility to infection.

\section{Materials and Methods}

\section{Study Enrollment}

A total of 213 VLBWIs, who had been admitted to our NICU between April 2009 and March 2014, participated in this study. After the Institutional Review Board had approved the study protocol, informed consent was obtained from the respective caretakers of all patients. We excluded patients $(n=10)$ who suffered from chromosomal abnormalities, major constitutional anomalies or inherited diseases including hemophagocytic lymphohistiocytosis and neonatal hemochromatosis. Twenty patients died before discharge. Seven patients declined to participate in the study. Hence, a total of 176 (82.6\%) VLBWIs (86 males and 90 females) were finally registered for the study (fig. 1).

\section{Clinical Data Collection}

Clinical data were collected including previous obstetric history, the current pregnancy and delivery, infant morbidity and treatment. Estimated gestational age was determined as the best obstetric estimate according to the last menstrual period, standard

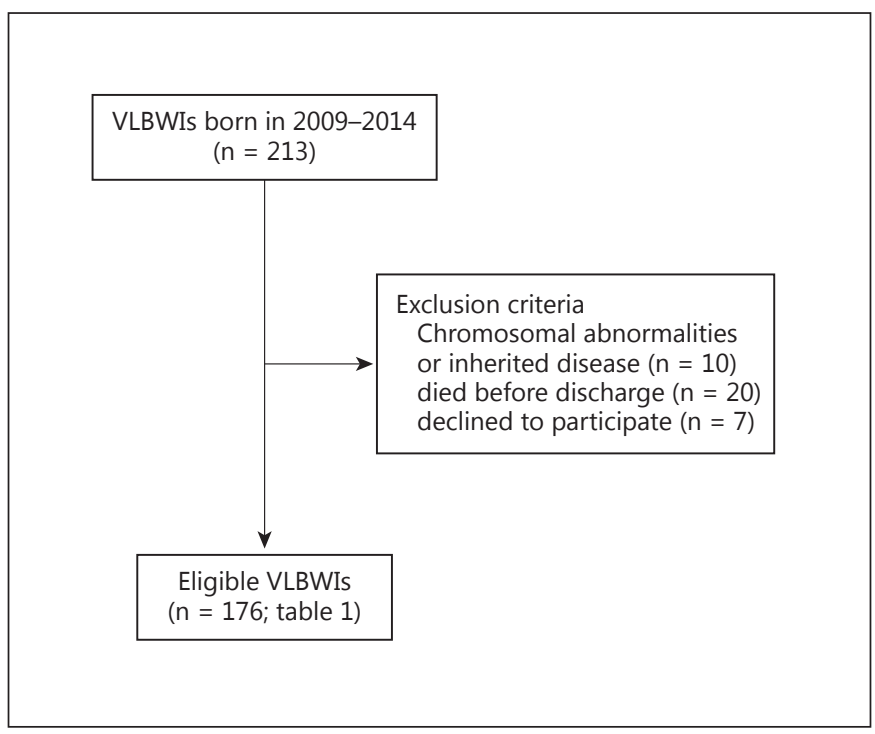

Fig. 1. Outline of our study.

obstetric parameters and ultrasonographic findings. Infants with a birth weight $(\mathrm{BW})$ of $>10$ th percentile below the mean of the birth size standard data of Japanese patients were classified as small for gestational age (SGA) infants [9]. All survivors received brain magnetic resonance imaging (MRI) before hospital discharge. IVH was classified according to the grading scale by Papile et al. [10]. PVL was defined as cyst formation or ventricular enlargement with irregular walls on the MRI. ROP was defined in accordance with the international classification. Intestinal perforation was defined according to radiological or operative evidence. The clinical severity of BPD was defined by the duration of oxygen supplementation and positive pressure, i.e. positive pressure ventilation $(\mathrm{PPV})$ or nasal continuous positive airway pressure (NCPAP), and the diagnostic criteria recommended by the National Institute of Child Health and Human Development/ National Heart, Lung and Blood Institute/Office of Rare Diseases (NICHD/NHLBI/ORD) Workshop 2001 [11].

\section{Management of Iron Supplementation, Erythropoietin} Administration and Blood Transfusion

According to the guideline for iron supplementation for preterm infants from the Japan Society for Premature and Newborn Medicine 2003, elemental iron supplementation was started at a dose of $6 \mathrm{mg} / \mathrm{kg}$ of soluble ferric pyrophosphate INCREMIN $^{\circledR}$ Syrup 5\%, Alfresa Pharma Ltd., Osaka, Japan) as soon as $100 \mathrm{ml} /$ $\mathrm{kg} /$ day of enteral feeding was tolerated. The supplementation was continued during the admission period. All VLBWIs received recombinant human erythropoietin (EPO) $\left(\mathrm{ESPO}^{\mathrm{R}}\right.$, Kirin Brewery Ltd., Tokyo, Japan) subcutaneously at a dose of $200 \mathrm{IU} / \mathrm{kg}$ twice a week. EPO therapy was started when the hemoglobin $(\mathrm{Hb})$ level was $<12 \mathrm{~g} / \mathrm{dl}$, and continued unless the level increased to $10 \mathrm{~g} / \mathrm{dl}$. Restrictive red blood cell (RBC) transfusions were performed following the guideline of the Japanese Red Cross Society. Infants who (1) were on any mechanical respiratory support or oxygen supplementation with anemia of prematurity were considered for 
blood transfusion according to their disabilities, (2) did not suffer from respiratory disturbance were not transfused unless their $\mathrm{Hb}$ was $<8 \mathrm{~g} / \mathrm{dl}$ and (3) suffered from anemic symptoms (e.g. persistent tachycardia, persistent tachypnea, apnea, inactivity, feeding disorder or failure to thrive), were not transfused unless their $\mathrm{Hb}$ was $<10 \mathrm{~g} / \mathrm{dl}$. A standard transfusion volume of $10-20 \mathrm{ml} / \mathrm{kg}$ packed RBCs was used.

\section{Monitoring the Iron and Hematological Status}

The hematological status of all admitted infants was surveyed from arterial or venous blood samples at birth and at 2, 4, 8 and 12 postnatal weeks of age. We evaluated the iron status according to serum levels of iron, unbound iron-binding capacity and ferritin, in addition to the results of routinely surveyed the biochemistry and complete blood cell counts. The ferritin level was measured by the latex turbidimetric immunoassay method. Hyperferritinemia was defined as a value of $\geq 500 \mathrm{ng} / \mathrm{ml}$ of the serum ferritin according to the Japanese guideline for the treatment of iron overload [12]. The complete blood cell count and reticulocyte count (RETI) were measured using automated Beckman Coulter hematology analyzers (Beckman Coulter Inc., Miami, Fla., USA).

\section{Statistical Analysis}

Statistical analyses were performed using the JMP ${ }^{\circledR} 11$ software program (SAS Institute Inc., Cary, N.C., USA). Differences between groups were tested for significance with the $\chi^{2}$ test. For nonparametric techniques, an association study involving continuous variables was analyzed using Spearman's rank-sum test. In a multivariate analysis, multilinear and logistic regression analyses were used for the continuous variables and the comparisons of continuous variables between subgroups, respectively. Dependent variables with a $\mathrm{p}$ value $<0.05$ in the univariate analysis were entered into the multivariate model. Results with $p$ values of $<0.05$ were considered to be significant.

\section{Results}

\section{Clinical Features of the Registered VLBWIs}

We first characterized the clinical features of the 176 VLBWIs (table 1). The median BW was $1,002 \mathrm{~g}$ (range $362-1,480 \mathrm{~g}$ ) and median gestational age was 28.5 weeks (range 22.6-36.1 weeks). Seventy (39.8\%) infants presented with the SGA phenotype. Twenty-three (13.1\%) of them underwent surgical ligation for patent ductus arteriosus (PDA). Twenty-three (13.1\%) infants developed proven sepsis. Twenty-nine (16.6\%) were diagnosed as having 'moderate or severe states of BPD' according to the definition and diagnostic criteria for BPD [11]. Packed RBCs were transfused to 61 (34.7\%) infants, and the median number of transfusions was 0 (range 0-14). Thus, the clinical features of VLBWIs in this study were consistent with previous results in a tertiary NICU in Japan [1].
Table 1. Clinical features of 176 VLBWIs

\begin{tabular}{lc}
\hline Male gender & $86(48.9)$ \\
BW, g & $1,002(362-1,480)$ \\
Gestational age, weeks & $28.5(22.6-36.1)$ \\
SGA & $70(39.8)$ \\
1-min Apgar & $6(0-9)$ \\
5-min Apgar & $8(1-10)$ \\
Multiple birth & $30(17.0)$ \\
PROM & $45(25.6)$ \\
PIH & $51(29.0)$ \\
Placenta previa & $9(5.1)$ \\
Placental abruption & $8(4.5)$ \\
ANS & $78(44.3)$ \\
CS & $132(75.0)$ \\
Surfactant & $115(65.3)$ \\
Pulmonary hemorrhage & $11(6.3)$ \\
Ligation & \\
Postnatal steroids & $23(13.1)$ \\
Intestinal perforation & $64(36.4)$ \\
IVH $\geq$ grade III & $9(5.1)$ \\
PVL & $11(6.2)$ \\
PC & $11(6.2)$ \\
Proven sepsis & $30(17.0)$ \\
Moderate-to-severe BPD & $23(13.1)$ \\
Blood transfusion & $29(16.6)$ \\
Transfusions, $n$ & $61(34.7)$ \\
\hline
\end{tabular}

Values are expressed as n (\%) or median (range). ANS = Antenatal steroid therapy; $\mathrm{CS}=$ Cesarean section; $\mathrm{PIH}=$ pregnancyinduced hypertension.

a Surgical ligation for PDA.

${ }^{\mathrm{b}}$ Based on the clinical criteria of BPD severity from the NICHD/ NHLBI/ORD Workshop 2001.

\section{Kinetics of the Iron and Hematological Status}

In the next step, we analyzed the hematological and biochemical status of the VLBWIs up to 12 postnatal weeks of age. A physiological downward tendency was observed in $\mathrm{Hb}$ (fig. 2b) and hematocrit values (fig. 2c). The RETI decreased from birth to 2 weeks, but increased over 4 weeks under EPO therapy (fig. 2d). There was a trend toward a greater unbound iron-binding capacity (fig. 2f), but not a higher level of iron (fig. 2e), with increasing postnatal age. Hyperferritinemia (i.e. a ferritin level $\geq 500 \mathrm{ng} / \mathrm{ml}$ ) was observed in $3(2.7 \%), 12$ (7.8\%), 13 $(7.8 \%), 3(4.1 \%)$ and $2(3.8 \%)$ patients on day 0 and at 2 , 4,8 and 12 weeks of age, respectively (fig. $2 \mathrm{~g}$ ). Interestingly, 24 (13.6\%) of all the VLBWIs displayed a state of hyperferritinemia at any point. 


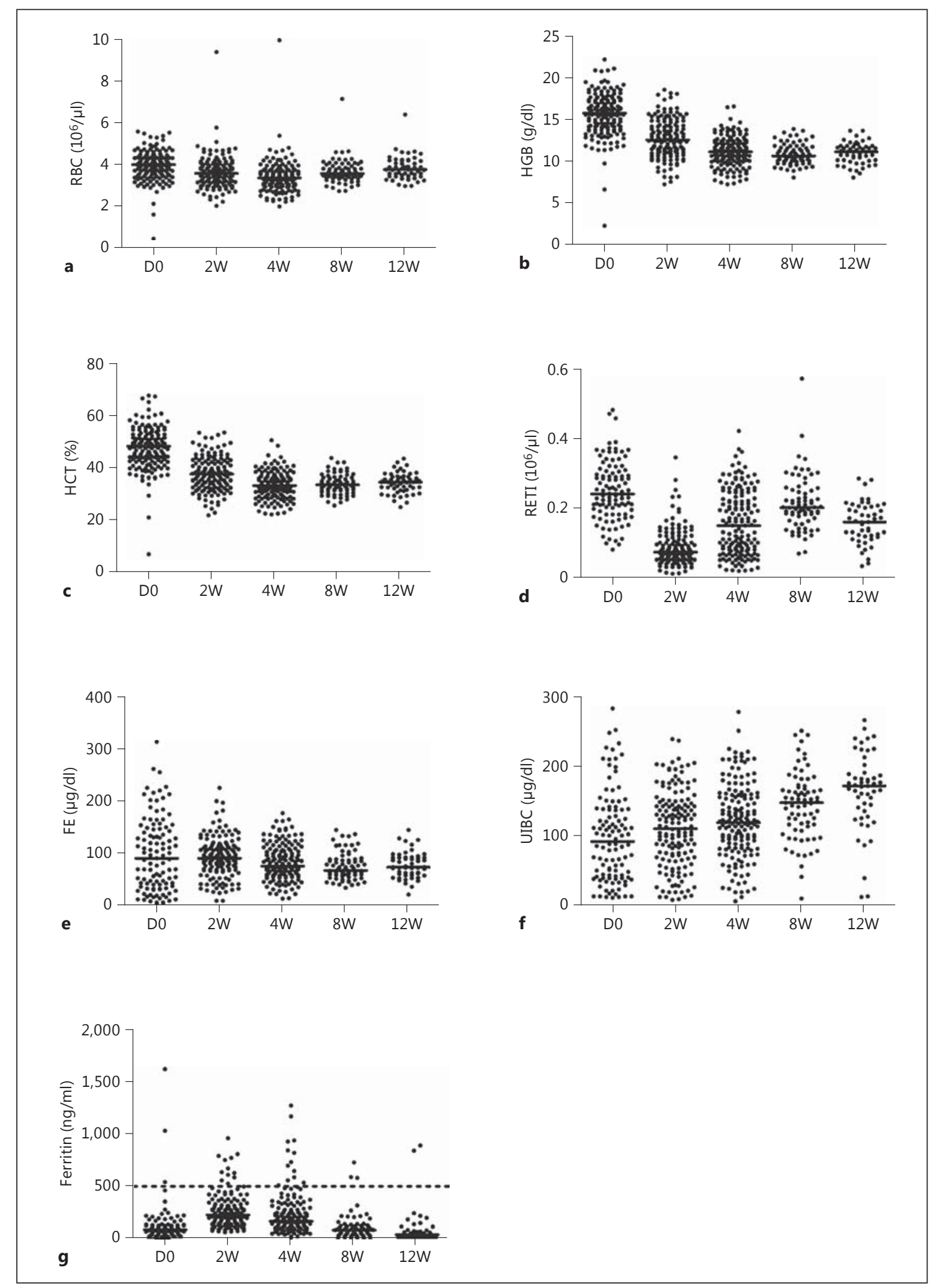

Fig. 2. a-g Hematological and biochemical status of the VLBWIs up to 12 postnatal weeks of age. The horizontal line shows the median of each measured value $(\bullet)$. g Kinetics of serum ferritin from birth to 12 postnatal weeks of age. The dashed line represents $500 \mathrm{ng} / \mathrm{ml}$ of serum ferritin. 
Table 2. Clinical variables associated with hyperferritinemia

\begin{tabular}{|c|c|c|c|c|c|c|}
\hline \multirow[t]{3}{*}{ Variables } & \multicolumn{6}{|c|}{ Hyperferritinemia $(\mathrm{n}=24)$} \\
\hline & \multicolumn{3}{|c|}{ univariate } & \multicolumn{3}{|c|}{ multivariate } \\
\hline & OR & $95 \% \mathrm{CI}$ & $\mathrm{p}$ value & OR & $95 \% \mathrm{CI}$ & $\mathrm{p}$ value \\
\hline Male gender & 1.05 & $0.45-2.49$ & 0.54 & & & \\
\hline SGA & 0.55 & $0.23-1.32$ & 0.19 & & & \\
\hline Multiple birth & 2.31 & $0.86-6.19$ & 0.08 & & & \\
\hline PROM & 0.54 & $0.17-1.68$ & 0.21 & & & \\
\hline PIH & 1.01 & $0.39-2.61$ & 0.57 & & & \\
\hline Placenta previa & - & - & 0.26 & & & \\
\hline Placental abruption & 0.90 & $0.11-7.66$ & 0.70 & & & \\
\hline ANS & 0.59 & $0.24-1.45$ & 0.17 & & & \\
\hline CS & 1.31 & $0.46-3.75$ & 0.41 & & & \\
\hline Surfactant & 1.70 & $0.64-4.54$ & 0.20 & & & \\
\hline Pulmonary hemorrhage & 1.44 & $0.29-7.13$ & 0.46 & & & \\
\hline Ligation $^{\mathrm{a}}$ & 5.91 & $2.19-16.0$ & $<0.01$ & 7.01 & $1.41-34.9$ & 0.02 \\
\hline Postnatal steroids & 1.92 & $0.81-4.58$ & 0.10 & & & \\
\hline Intestinal perforation & 3.60 & $0.99-13.1$ & 0.06 & & & \\
\hline IVH $\geq$ grade III & 15.2 & $4.04-57.4$ & $<0.01$ & 4.91 & $0.98-24.7$ & 0.05 \\
\hline PVL & 1.44 & $0.29-7.13$ & 0.46 & & & \\
\hline PC for ROP & 3.74 & $1.45-9.64$ & $<0.01$ & 0.50 & $0.12-2.10$ & 0.35 \\
\hline Proven sepsis & 5.91 & $2.19-16.0$ & $<0.01$ & 4.24 & $1.13-15.9$ & 0.03 \\
\hline Moderate-to-severe $\mathrm{BPD}^{\mathrm{b}}$ & 10.0 & $3.86-26.1$ & $<0.01$ & 7.50 & $1.89-29.8$ & $<0.01$ \\
\hline Blood transfusion & 5.96 & $2.31-15.4$ & $<0.01$ & 0.96 & $0.22-4.24$ & 0.96 \\
\hline
\end{tabular}

Logistic regression analysis was used to investigate the independent variables with hyperferritinemia (serum ferritin $>500 \mathrm{ng} / \mathrm{ml}$ ). Clinical variables with a p value $<0.05$ in the univariate analysis were entered into the multivariate logistic model. Bold values indicate statistical significance. ANS = Antenatal steroid therapy; $\mathrm{CS}=\mathrm{Ce}$ sarean section; $\mathrm{PIH}$ = pregnancy-induced hypertension; $\mathrm{PROM}=$ premature rupture of membranes.

a Surgical ligation for PDA.

$\mathrm{b}$ Based on the clinical criteria of BPD severity from the NICHD/NHLBI/ORD Workshop 2001.

\section{Clinical and Biochemical Parameters Associated with} Hyperferritinemia

We next investigated whether the clinical factors of the VLBWIs up to 12 postnatal weeks of age may be associated with hyperferritinemia (table 2). When assessed by univariate analysis, hyperferritinemia was significantly associated with surgical ligation [odds ratio (OR) 5.91, 95\% confidence interval (CI) 2.19-16.0, p $<0.01$ ], IVH (OR 15.2, 95\% CI 4.04-57.4, $\mathrm{p}<0.01$ ), photocoagulation (PC) for ROP (OR 3.74, 95\% CI 1.45-9.64, p < 0.01), proven sepsis (OR 5.91, 95\% CI 2.19-16.0, p < 0.01), a moderate to severe state of BPD (OR 10.0, 95\% CI 3.8626.1, p < 0.01) and blood transfusion (OR 5.96, 95\% CI $2.31-15.4, \mathrm{p}<0.01)$. Additionally, a multiple logistic analysis selected 3 factors associated with hyperferritinemia: ligation (OR 7.01, 95\% CI 1.41-34.9, $\mathrm{p}=0.02$ ), sepsis (OR $4.24,95 \%$ CI 1.13-15.9, $\mathrm{p}=0.03$ ) and BPD (OR 7.50, 95\% CI 1.89-29.8, $\mathrm{p}<0.01)$.
We further explored whether biochemical parameters might be associated with the value of ferritin and found that the serum level of ferritin was significantly correlated with the values of aspartate transaminase (AST), creatine kinase (CK) and C-reactive protein (CRP) on the analysis. We also verified these correlations in AST [partial regression coefficient (rc) 2.23, 95\% CI 1.76-2.72, p $<0.01$ ], CK (rc $-0.28,95 \%$ CI -0.37 to $-0.18, \mathrm{p}<0.01$ ) and CRP (rc $40.2,95 \%$ CI $4.72-75.6, \mathrm{p}=0.03$ ) according to a multilinear regression analysis (table 3).

\section{Clinical Factors Excluded the Outlier Data of Hyperferritinemia}

We excluded the data of patients $(n=13)$ with CRP $>0.5 \mathrm{mg} / \mathrm{dl}$ or abnormal AST or CK values which were determined by Smirnov-Grubbs' test with a $\mathrm{p}$ value $<0.05$, because these patients might have had infectious disease or have suffered from other pathological conditions which affected their serum ferritin values. Accord- 
Table 3. Biochemical items associated with serum ferritin levels

Table 4. Clinical variables excluding the outlier data of hyperferritinemia

\begin{tabular}{|c|c|c|c|c|c|c|}
\hline \multirow[t]{2}{*}{ Items } & \multicolumn{3}{|c|}{ Univariate } & \multicolumn{3}{|c|}{ Multivariate } \\
\hline & $\mathrm{n}$ & $\mathrm{CC}$ & $\mathrm{p}$ & $\mathrm{rc}$ & $95 \% \mathrm{CI}$ & $\mathrm{p}$ \\
\hline AST & 558 & -0.20 & $<0.01$ & 2.23 & 1.76 to 2.72 & $<0.01$ \\
\hline ALT & 557 & -0.06 & 0.20 & & & \\
\hline $\mathrm{LDH}$ & 555 & 0.04 & 0.36 & & & \\
\hline CK & 557 & -0.36 & $<0.01$ & -0.28 & -0.37 to -0.18 & $<0.01$ \\
\hline CRP & 554 & 0.32 & $<0.01$ & 40.2 & 4.72 to 75.6 & 0.03 \\
\hline
\end{tabular}

Biochemical items with a $\mathrm{p}$ value $<0.05$ in the univariate analysis were entered into the multiple regression analysis. Bold values indicate statistical significance. ALT = Alanine transaminase; $\mathrm{cc}=$ correlation coefficient; $\mathrm{LDH}=$ lactate dehydrogenase.

\begin{tabular}{|c|c|c|c|c|c|c|}
\hline \multirow[t]{3}{*}{ Variables } & \multicolumn{6}{|c|}{ Hyperferritinemia $(\mathrm{n}=11)^{\mathrm{a}}$} \\
\hline & \multicolumn{3}{|c|}{ univariate analysis } & \multicolumn{3}{|c|}{ multivariate analysis } \\
\hline & OR & $95 \% \mathrm{CI}$ & $\mathrm{p}$ & OR & $95 \% \mathrm{CI}$ & $\mathrm{p}$ \\
\hline Male gender & 1.28 & $0.37-4.34$ & 0.47 & & & \\
\hline SGA & 1.41 & $0.50-3.96$ & 0.34 & & & \\
\hline Multiple birth & 1.09 & $0.22-5.31$ & 0.59 & & & \\
\hline PROM & 0.28 & $0.03-2.21$ & 0.18 & & & \\
\hline $\mathrm{PIH}$ & 0.91 & $0.23-3.57$ & 0.60 & & & \\
\hline Placenta previa & - & - & 0.55 & & & \\
\hline Placental abruption & - & - & 0.59 & & & \\
\hline ANS & 0.26 & $0.05-1.24$ & 0.06 & & & \\
\hline CS & 0.88 & $0.22-3.48$ & 0.55 & & & \\
\hline Surfactant & 2.50 & $0.52-12.0$ & 0.20 & & & \\
\hline Pulmonary hemorrhage & 1.55 & $0.18-13.3$ & 0.52 & & & \\
\hline Ligation $^{\mathrm{b}}$ & 2.72 & $0.67-11.1$ & 0.16 & & & \\
\hline Postnatal steroids & 1.00 & $0.28-3.56$ & 0.62 & & & \\
\hline Intestinal perforation & 1.40 & $0.16-12.0$ & 0.55 & & & \\
\hline IVH $\geq$ grade III & 3.85 & $0.72-20.5$ & 0.14 & & & \\
\hline PVL & & & 0.48 & & & \\
\hline $\mathrm{PC}$ & 4.67 & $1.32-16.5$ & 0.02 & 2.20 & $0.46-10.6$ & 0.32 \\
\hline Proven sepsis & 4.39 & $1.18-16.4$ & 0.04 & 2.21 & $0.50-9.81$ & 0.30 \\
\hline $\mathrm{BPD}$ & 2.84 & $0.83-9.75$ & 0.09 & & & \\
\hline Moderate-to-severe ${ }^{c}$ & 4.90 & $1.38-17.3$ & 0.02 & 2.00 & $0.38-10.6$ & 0.41 \\
\hline Blood transfusion & 3.60 & $1.01-12.8$ & 0.04 & 1.46 & $0.27-7.83$ & 0.66 \\
\hline
\end{tabular}

Logistic regression analysis was used to investigate the independent variables with hyperferritinemia. Clinical variables with a $\mathrm{p}$ value $<0.05$ in the univariate analysis were entered into the multivariate logistics model. Bold values indicate statistical significance. ANS = Antenatal steroid therapy; CS = Cesarean section; $\mathrm{PIH}=$ pregnancy-induced hypertension; $\mathrm{PROM}=$ premature rupture of membranes.

${ }^{\text {a }}$ The outlier data were deleted based on the criteria as follows: the data with CRP $<0.5$ $\mathrm{mg} / \mathrm{dl}$, AST and CK using the Smirnov-Grubbs test with a $\mathrm{p}$ value $<0.05$.

$\mathrm{b}$ Surgical ligation for PDA.

${ }^{c}$ Based on the clinical criteria of BPD severity from the NICHD/NHLBI/ORD Workshop 2001. 
ing to univariate analysis, hyperferritinemia was significantly associated with PC (OR 4.67, 95\% CI 1.32-16.5, $\mathrm{p}=0.02)$, sepsis (OR 4.39, 95\% CI 1.18-16.4, $\mathrm{p}=0.04)$, moderate to severe BPD (OR 4.90, 95\%CI 1.38-17.3, $\mathrm{p}=0.02$ ) and transfusion (OR 3.60, 95\% CI 1.01-12.8, $\mathrm{p}=0.04)$. Conversely, the value of ferritin did not show significant associations between any of the clinical variables according to the multivariate analysis (table 4).

\section{Discussion}

This study investigated the iron and hematological status of VLBWIs and their relationship with clinical features. In 176 VLWBIs, packed RBCs were transfused to 61 (34.7\%) infants. The increase of RETI, which began after $>4$ weeks of EPO therapy was associated with a coincidental decline in iron level and an increase in unbound iron-binding capacity. Twenty-four (13.6\%) infants displayed a state of hyperferritinemia. The multiple logistics analysis selected 3 factors associated with hyperferritinemia: surgical ligation for PDA, proven sepsis and a moderate-to-severe state of BPD. In addition, we verified that the value of serum ferritin was significantly correlated with AST, CK and CRP values according to the multilinear regression analysis. After the exclusion of data with outliers for AST, CK or CRP, we did not identify any factors associated with hyperferritinemia, suggesting that hyperferritinemia in patients with persistent PDA, sepsis or BPD was associated with high levels of AST, CK and CRP.

During surgical closure for PDA, infants often receive massive intraoperative transfusion for stabilization of the hemodynamic state. Well-established risks associated with acute transfusions include hemolytic reactions. Bell et al. [13] reported that there was no difference in the risk of surgical closure ( $4 \mathrm{vs.} 8 \%$ ) between a liberal transfusion group (5.2 \pm 4.5 times of transfusion) and a restrictive transfusion group $(3.3 \pm 2.9)$. A systematic review also concluded there was no clear difference in the mortality, duration of ICU stay or other adverse events between transfusion strategies for patients undergoing cardiac surgery for congenital heart disease [14]. Prior to cardiac surgery, prophylactic gradual transfusion might prevent hyperferritinemia in such infants.

Transfusion of packed RBCs was previously shown to be related to the occurrence of nosocomial infection, and there was a dose-response pattern in critically ill patients [15]. An elevated ferritin level might impair the host response to infection. Additionally, iron excess results in an increase in the anti-inflammatory cytokines, IL-4, IL-6 and IL-10. Similarly, excess iron alters the normal balance of $\mathrm{T}$ helper cells, resulting in a decrease in type $1(\mathrm{CD} 8+)$ and an increase in type 2 (CD4+) cells [16]. However, the precise mechanism involved remains unclear in preterm birth infants [4]. There is a significant positive correlation between the volume of blood transfusions received and the levels of malondialdehyde, a biochemical marker of lipid peroxidation, from the pulmonary epithelial lining fluid in premature babies [17]. The number and volume of transfusions have also been shown to be predictors of BPD [18]. In this study, we did not examine the total volume or the date of transfusion in each patient, making it not possible to detect a direct causal relationship between blood transfusion and hyperferritinemia.

The vast majority of iron is located intracellularly and is sequestered within ferritin as the iron storage protein [7]. Therefore, serum ferritin is recognized to be one of the cellular proteins like AST, alanine transaminase, lactate dehydrogenase and CK. Iron staining of liver tissue demonstrates that excess iron initially accumulates in Kupffer cells or macrophages, and with a progressive increase in iron accumulation, this excess overwhelms the hepatocytes [19]. The elevated AST in our VLBWIs might have been a reflection of hepatotoxicity as a result of iron deposition in the hepatocytes.

Serum ferritin often increases in the presence of inflammation or malignancy. Endotoxin was reported to transcriptionally upregulate the ferritin coding gene [20]. However, it is unclear whether serum ferritin reflects or causes inflammation, or whether it is involved in an inflammatory cycle. A cross-sectional study in Chilean children revealed that the serum CRP level was positively associated with the serum ferritin and zinc protoporphyrin levels [21]. A meta-analysis estimated that $49.6 \%$ of the inflammatory state (i.e. CRP $\geq 5 \mathrm{mg} / \mathrm{l}$ ) was associated with elevated ferritinemia [22]. Hence, the prevalence of hyperferritinemia in this study might have been overestimated in the event of inflammatory conditions. Conversely, ferritin and CRP were both expected to be acutephase reactants. Therefore, surgical ligation for PDA, sepsis and a severe state of BPD could all involve components of inflammation.

In this study, we evaluated the iron status using a residual serum sample from a routine hematological survey. The lack of samples might represent a bias because it could indicate that the number of infants with hyperferritinemia was underestimated. It has been reported that several molecules other than ferritin are involved in iron homeostasis $[23,24]$. Future studies are required to vali-
Ochiai/Kurata/Inoue/Tanaka/Matsushita/ Fujiyoshi/Wakata/Kato/Taguchi/Takada 
date the molecular mechanism of hepcidin as an ironregulating molecule as well as oxidants and pro/anti-inflammatory cytokines in hyperferritinemia in VLBWIs.

\section{Conclusion}

We revealed that some VLBWIs treated in the NICU have an increased risk of hyperferritinemia and that pathological conditions might be associated with oxygen radical disease and susceptibility to infection. Iron chelation therapy has been successfully conducted in pediatric oncology patients [25]. It is anticipated that such pathologyspecific interventions will reduce mortality and morbidity in such high-risk preterm infants.

\section{Acknowledgments}

The authors would like to thank Y. Takahata, M. Ichiyama,T. Kinjo and the present fellows of our institution for treating the patients, and T. Tanaka and A. Tahara for valuable technical advice on the measurement system. The study was supported in part by the Morinaga Foundation (K.T.) and the KAKEN, No. 15K09717 (M.O.), No. 26860809 (H.I.), No. 15K20345 (J.F.) and No. 16K19688 (J.F.).

\section{Disclosure Statement}

The authors have no financial relationship relevant to this article to disclose.

\section{References}

1 Kusuda S, Fujimura M, Uchiyama A, Totsu S, Matsunami K, Network NR: Trends in morbidity and mortality among very-low-birthweight infants from 2003 to 2008 in Japan. Pediatr Res 2012;72:531-538.

2 Ochiai M, Kinjo T, Takahata Y, Iwayama M, Abe T, Ihara K, Ohga S, Fukushima K, Kato K, Taguchi T, Hara T: Survival and neurodevelopmental outcome of preterm infants born at 22-24 weeks of gestational age. Neonatology 2014;105:79-84.

3 Winterbourn CC: The ability of scavengers to distinguish $\mathrm{OH}$. production in the iron-catalyzed haber-weiss reaction: comparison of four assays for $\mathrm{OH}$. Free Radic Biol Med 1987;3:33-39.

4 Collard KJ: Iron homeostasis in the neonate. Pediatrics 2009; 123:1208-1216.

5 Marseglia L, D'Angelo G, Manti S, Arrigo T, Barberi I, Reiter RJ, Gitto E: Oxidative stressmediated aging during the fetal and perinatal periods. Oxid Med Cell Longev 2014;2014: 358375.

6 Saugstad OD: Bronchopulmonary dysplasia - oxidative stress and antioxidants: Semin Neonatol 2003;8:39-49.

7 Skaar EP: The battle for iron between bacterial pathogens and their vertebrate hosts. PLoS Pathog 2010;6:e1000949.

8 Ozment CP, Turi JL: Iron overload following red blood cell transfusion and its impact on disease severity. Biochim Biophys Acta 2009; 1790:694-701.

9 Yoshida SH, Unno N, Kagawa H, Shinozuka N, Kozuma S, Taketani Y: Sonographic determination of fetal size from 20 weeks of gestation onward correlates with birth weight. J Obstet Gynaecol Res 2001;27:205-211.
10 Papile LA, Burstein J, Burstein R, Koffler H: Incidence and evolution of subependymal and intraventricular hemorrhage: a study of infants with birth weights less than $1,500 \mathrm{~g}$. J Pediatr 1978;92:529-534.

11 Jobe AH, Bancalari E: Bronchopulmonary dysplasia. Am J Respir Crit Care Med 2001; 163:1723-1729.

12 Suzuki T, Tomonaga M, Miyazaki Y, Nakao S, Ohyashiki K, Matsumura I, Kohgo Y, Niitsu Y, Kojima S, Ozawa K: Japanese epidemiological survey with consensus statement on Japanese guidelines for treatment of iron overload in bone marrow failure syndromes. Int J Hematol 2008;88:30-35.

13 Bell EF, Strauss RG, Widness JA, Mahoney LT, Mock DM, Seward VJ, Cress GA, Johnson KJ, Kromer IJ, Zimmerman MB: Randomized trial of liberal versus restrictive guidelines for red blood cell transfusion in preterm infants. Pediatrics 2005;115:1685-1691.

14 Wilkinson KL, Brunskill SJ, Doree C, Trivella M, Gill R, Murphy MF: Red cell transfusion management for patients undergoing cardiac surgery for congenital heart disease. Cochrane Database Syst Rev 2014;2:CD009752.

15 Taylor RW, O’Brien J, Trottier SJ, Manganaro L, Cytron M, Lesko MF, Arnzen K, Cappadoro C, Fu M, Plisco MS, Sadaka FG, Veremakis C: Red blood cell transfusions and nosocomial infections in critically ill patients. Crit Care Med 2006;34:2302-2308; quiz 2309.

16 Schaible UE, Kaufmann SH: Iron and microbial infection. Nat Rev Microbiol 2004;2:946953.

17 Collard KJ, Godeck S, Holley JE: Blood transfusion and pulmonary lipid peroxidation in ventilated premature babies. Pediatr Pulmonol 2005;39:257-261.
18 Korhonen P, Tammela O, Koivisto AM, Laippala P, Ikonen S: Frequency and risk factors in bronchopulmonary dysplasia in a cohort of very low birth weight infants. Early Hum Dev 1999;54:245-258.

19 Batts KP: Iron overload syndromes and the liver. Mod Pathol 2007;20(suppl 1):S31-S39.

20 Ong DS, Wang L, Zhu Y, Ho B, Ding JL: The response of ferritin to LPS and acute phase of Pseudomonas infection. J Endotoxin Res 2005; 11:267-280.

21 Brito A, Hertrampf E, Olivares M: Iron status biomarkers and $\mathrm{C}$-reactive protein in children aged 19 to 72 months in Chile. Food Nutr Bull 2013;34:14-20.

22 Thurnham DI, McCabe LD, Haldar S, Wieringa FT, Northrop-Clewes CA, McCabe GP: Adjusting plasma ferritin concentrations to remove the effects of subclinical inflammation in the assessment of iron deficiency: a meta-analysis. Am J Clin Nutr 2010;92:546555.

23 Kitajima J, Ohga S, Kinjo T, Ochiai M, Takahata Y, Honjo S, Hara T: Serum prohepcidin concentrations at birth and 1 month after birth in premature infants. Pediatr Blood Cancer 2011;56:267-272.

24 Inoue H, Ohga S, Kusuda T, Kitajima J, Kinjo T, Ochiai M, Takahata Y, Honjo S, Hara T: Serum neutrophil gelatinase-associated lipocalin as a predictor of the development of bronchopulmonary dysplasia in preterm infants. Early Hum Dev 2013;89:425-429.

25 Sait S, Zaghloul N, Patel A, Shah T, Iacobas I, Calderwood S: Transfusion related iron overload in pediatric oncology patients treated at a tertiary care centre and treatment with chelation therapy. Pediatr Blood Cancer 2014;61: 2319-2320. 